\title{
Sports Pharmacy as an emerging health science field; A perspective on the global and national scope Nida Khan ${ }^{1}$,Shamoon Noushad, ${ }^{1}$ \& Sadaf Ahmed ${ }^{1,2}$ \& 3
}

${ }^{1 .}$ Dadabouy Institue of Higher Education

2. Advance Educational Institute \& Research Center

3. University of Karachi

Corresponding Author Email: nida@ aeirc-edu.com Received 25/2/2018; Accepted 16/3/2018; Published 31/3/2018

\section{Abstract}

Background: Sports Pharmacy is an emerging field globally that has developed from in connection with health, economic and social sectors. The main reason of its importance has been taken into account for research and implementation in the prevention of doping, delivery systems, compounding medications and dietary supplements. Though there is a dire need of developing $\mathrm{f}$ sports Pharmacy as a separate field in Pakistan and to address hindrances in its progress.

Methodology: A short communication of 20 years i.e. 1998-2018. Databases used are Google Scholar, PubMed, Research gate, Scopus, The Nation news, BBC news.

Results: The significant highlights include that there is a usual partaking of the populace in sport and exercise at personal and professional levels and at every level, there is a need for advice about general healthcare and associated therapies for better performance and wellbeing. It is also identified that there is a growing need for specialist pharmacists in the area of sport and exercise in order to fulfill this valuable healthcare role. These specialists may be described as sports pharmacist's development of Sports pharmacy in Pakistan. Prevention of doping worldwide reduced significantly with the help of pharmacist expertise.

Conclusion: Sports pharmacy can be helpful in changing some healthcare aspects regarding sports worldwide. For the development of sports pharmacy in Pakistan, serious arrangements need to be taken.

\section{Keywords}

Sports-pharmacy, Doping, emerging, dietary supplements

\section{Introduction}

Sports is one of the dynamic forefront of healthcare; economic and sociopolitical supports globally and thus considered an important part of the society ${ }^{1}$. However, due to closely associated healthcare domains involved in Sports and exercise, for example, usage of medicines and supplementation, there are evident consequences of use and abuse. Self-medication and media influence are other factors that have raised the threats from such medicines and dietary supplements nowadays ${ }^{2}$.

Doping in sports has become one of the most serious public health concern which shows no significant decrease in doping usage, not even in Olympic Games $^{4-7}$. The average prevalence of doping in amateur sport is found to be $12 \%$ in professional sportsmen or women; $62 \%$ of amateurs, $21 \%$ are semi-professional, and $5 \%$ are coaches ${ }^{8}$. For the prevention of doping an agency was developed in 1999 with the name of World Anti-Doping Code, the agency included all abusive agents in a published list "Prohibited Substances and Methods"

${ }^{9-10}$. Doping and steroids abuse are one of the known reason for cardiovascular diseases and deaths in sports world ${ }^{11}$. Therefore, a pharmacist should be the first priority in sports team to provide guidance ${ }{ }^{1}$. The international pharmaceutical federation (FIP) recognized that a pharmacist plays a vital role in the prevention of doping in sports and to make it a fair game ${ }^{12}$. 
Self-medication is one of the growing and important issue globally. It gives birth to misdiagnosis, adverse reactions, drug interaction, drug dosage and polypharmacy. It is particularly problematic for elderly drug use. To reduce such events it is necessary to engage pharmacists directly to patient counselling ${ }^{13}$.

There has been an immense need to regulate these banned or permitted medications and supplements. Therefore, an emerging field, Sports Pharmacy/Sports medicine has been taught and practiced worldwide. Sports medicine and sports pharmacy are interchangeable terms. Sports pharmacy regulates the use of such medications either as therapeutic or performance enhancing, there must be a relevant degree of expertise. Another component of sports pharmacy is doping control. Sports Pharmacy is the practice and training of pharmacist to empower them in playing an active role in anti-doping campaign ${ }^{3}$.

Olympic Games has now established pharmacy clinic services to athletes. This service is now currently serving 10,500 athletes regarding banned and supplements, 4200 Paralympic athletes from 170 countries and 9.2million spectators in 50 places $^{14}$. Sports pharmacy as the subject being caught in many first world countries.

Pakistan has been known worldwide for producing some infamous athletes in the field of cricket, snooker, tennis etc. In past few years, many athletes and bodybuilders died because of drug abuse ${ }^{15}$. Not only to fight against drug abuse, there is a need for sports pharmacy to develop more inspiring athletes and to promote health and sport. Because of many stressful incidents in Pakistan, it is necessary to divert public to a relaxing objective like sports ${ }^{16}$.

For the reason, this present literature review reflects the concept of Sports pharmacy and its development in Pakistan with relation to its scope worldwide. This paper aims to identify the core elements of Sports pharmacy, its emergence globally and factors associated with its progress in Pakistan.

\section{Methodology}

This Short communication literature review is of 20 years' timeline i.e. 1998-2018. Databases that are used to search literature review are Google Scholar, PubMed, Scopus and Research gate, BBC news, Olympic Games, The Nation News and World AntiDoping Agency. The Inclusion/exclusion criteria of this article were followed on the basis of authentic information, relevance to the topic, available research papers, and factual information.

\section{Results}

Following are some relevant case studies: in 2016, total five bodybuilders died in just 17 days. One of them was a South Asian Bodybuilding Championship (SABC) 2016 gold medalist, Rizwan, who died of choke, later it was revealed the athlete was on steroids. Another bronze medal winner became a victim of steroids in his 41 years of age ${ }^{14}$. Thus, recent many violations of the laws on globally banned drugs, increased death rates of a sports person and under satisfied health conditions in Pakistan have been observed. These all contribute to the development of Sports pharmacy and promotion of pharmacist as healthcare entity in Pakistan

\section{Discussion}

Many areas of health sciences required the expertise of pharmacy, for example, the pharmacist is involved in giving their knowledge in emergency medicine $^{17}$ and also involved in public health and community services ${ }^{18}$. Sports being one of such areas where competent pharmacists and knowledge of banned medications are equally required as clinicians. Athletes require pharmacy services to go along their doping tests and sports injuries. Specially non-prescribed medications, compounded medicines, and recording of these substances can be provided by a pharmacist ${ }^{3}$.

In September 2005, The International Pharmaceutical Federation approved standard statements regarding the role of Pharmacist ${ }^{19}$. Many studies have proved that pharmacist significantly plays a vital role in the prevention of banned drugs 
and promotion of safe and cost-effective medication in sport $^{20-22}$. Pharmacists not only helps in prevention of doping but sometimes also become part of its resource. Which will result because of under-appreciation of this profession and involvement of money ${ }^{23}$.

In Pakistan, past few years pharmacy profession has expanded largely in terms of numbers of graduates $^{24}$. Around 8102 pharmacists are currently present in Pakistan. Of which 55\% are involved in pharmaceuticals, $15 \%$ in regulatory and hospitals, $15 \%$ in sales and only $5 \%$ in research and teaching ${ }^{25}$. As compared to elsewhere, pharmacy profession is under-recognized in Pakistan. There are different reasons for lack of recognition these include lack of pharmacist interaction directly with patient and physician. Also because of lack of interest in community and research areas. A bizarre lawful situation on the regulation of drug manufacturing, distribution, selling and buying also concludes towards under-recognition of the pharmacy profession.

Due to the growing use of doping in sports, Sports and athletes in Pakistan are in great danger. Because of lack human resources, this profession also lacks government interest ${ }^{26}$. According to statistics of pharmacists in Pakistan, there seems no concept of sports pharmacy so far. In order to put things systematically in sports and to avoid sudden deaths of athletes and bodybuilders, Pakistan must develop a division for pharmacists.

\section{Conclusion}

This literature review has provided relevant studies about how pharmacy profession is involved in changing many healthcare aspects positively. Therefore, before developing sports pharmacy in Pakistan, there is a strong need to promote pharmacy profession to have it gain its rightful place as it does in rest of the world.

\section{Recommendations}

- To build human resources for this profession, pharmacists must be educated and trained regarding the field.

- There should be awareness sessions of sports pharmacy to promote the benefits of exercise through participation in sporting activities.

- To provide knowledge regarding the nutritional supplements and the risks associated with their use.

\section{Conflicts of interest}

None.

\section{Acknowledgment}

Team AEIRC has supported in editing this article.

\section{Funding}

None.

\section{References}

1. Awaisu A, Mottram D, Rahhal A, Alemrayat B, Ahmed A, Stuart M, Khalifa S. Knowledge and perceptions of pharmacy students in Qatar on Anti-Doping in sports and on sports pharmacy in undergraduate curricula. American Journal of Pharmaceutical Education. 2015; 79(8):119.

2. Ambrose PJ. Educational opportunities and anti-doping roles and responsibilities for pharmacists. Yakugaku Zasshi. 2011; 131(12):1761-4.

3. Ambrose PJ. An advanced pharmacy practice experience in sports pharmacy. American journal of pharmaceutical education. 2008;72(1):19

4. Birchard K. Olympic committee bans doctor after doping case. (2000).

5. Bahrke MS, Yesalis CE. The future of performance-enhancing substances in sport. The Physician and Sportsmedicine. 2002; 30(11):51-3.

6. International Olympic Committee. "Antidoping rules procedures \& violations at the Athens 2004 Olympic games." Retrieved from: http://www.olympic.org/Documents/Reports/E N/en_report_921.pdf), cited 20 March 2012. 
7. International Olympic Committee. Factsheet: The fight against doping and promotion of atheletes' health. Reterived from: http://sportsanddrugs.

procon.org/sourcefiles/IOCFactsheet2010.pdf> , cited 20 March, 2012.

8. Sapstead N. Doping in sport: drug use 'fast becoming a crisis', BBC sports, 2017 March.20. Retrieved form: http://www.bbc.com/sport/38884801)

9. World Anti-Doping Agency. The 2014 Prohibited List. 2014. Retrieved form: https://wada-mainprod.s3.amazonaws.com/resources/files/WAD ARevised-2014-Prohibited-List-EN.PDF.

10. World Anti-Doping Code. 2015. Retrieved from:

https://wadamainprod.s3.amazonaws.com/reso urces/files/wada_antidoping_code_2009_en_0. pdf. Accessed September 12014

11. Mirza F, Ahmed S. Psychological effects of using power-enhancing drugs on gymexercising individuals. International Journal of Pharmaceutical Sciences and Research. 2013; 4(4): 1565 .

12. FIP statement of professional standards: the role of the pharmacist in the fight against doping in sport. 2005. Retrieved from:http://www.fip.org/www/uploads/databas e_file.php?id5208\&table_id. Accessed August 3,2014

13. Hughes CM, McElnay JC, Fleming GF. Benefits and risks of self-medication. Drug safety. 2001; 24(14):1027-37.

14. Hayat Khezar, Roles of Pharmacist in Olympic Games, Pharmaceutical Journal. 2012.

15. The Nation 18 news.2016. Retrieved form:http://www.news18.com/news/othersports/4-bodybuilders-die-in-17-days-steroidswreak-havoc-in-pakistan-1232263.html
16. Noushad S, Ahmed S. Sorts and sources of stress in Pakistan; a comprehensive outlook. Ijehsr. 2013; 1(1):7

17. Cohen V, Jellinek SP, Hatch A, Motov S. Effect of clinical pharmacists on care in the emergency department: a systematic review. American Journal of Health-System Pharmacy. 2009; 66(15):1353-61

18. Eades CE, Ferguson JS, O'Carroll RE. Public health in community pharmacy: a systematic review of pharmacist and consumer views. BMC public health. 2011; 11(1):582.

19. International Pharmaceutical Federation. The Hague, The Netherlands; 2005. Available form: http://www.fip.org/www2/ statements/index.php?page 5statements\&state ments 5 statements_list Accessed December 21, 2006

20. Laure P, Kriebitzsch-Lejeune a. Retail pharmacists and doping in sports: knowledge and attitudes. A national survey in France. SciSports. 2000; 15(3):141-146.

21. Boyce EG, Vadher D. Introduction: Sports medicine and pharmacy: challenges for pharmacists and other health care professionals. J Pharm Pract. 2003; 16(1):3-4.

22. Alaranta A, Alaranta H, Helenius I. Use of prescription drugs in athletes. Sports Med. 2008; 38(6):449-463.

23. Ambrose PJ. Drug use in sports: a veritable arena for pharmacists. J Am Pharm Assoc. 2004; 44:501-16.

24. Report of the Health System Review Mission Pakistan, 2007.

25. Babar ZU. Going Back in Time. Chowk. 2007. Reterieved from: http://www.chowk.com/articles/12047

26. Azhar S, Hassali MA, Ibrahim MI, Ahmad M, Masood I, Shafie AA. The role of pharmacists in developing countries: the current scenario in Pakistan. Human Resources for Health. 2009; 7(1):54. 